\title{
Effects of composite viscosity and adhesive curing mode on marginal sealing of restorations
}

\section{Natália Cortez Gutierrez, Graziela Ribeiro Batista, Letícia Carvalho Coutinho} Costa Perote, Maria Beatriz Beber Kamozaki, Maria Amélia Máximo de Araújo \& Carlos Rocha Gomes Torres

To cite this article: Natália Cortez Gutierrez, Graziela Ribeiro Batista, Letícia Carvalho Coutinho Costa Perote, Maria Beatriz Beber Kamozaki, Maria Amélia Máximo de Araújo \& Carlos Rocha Gomes Torres (2017) Effects of composite viscosity and adhesive curing mode on marginal sealing of restorations, Journal of Adhesion Science and Technology, 31:21, 2349-2359, DOI: 10.1080/01694243.2017.1301072

To link to this article: https://doi.org/10.1080/01694243.2017.1301072

\section{Published online: 13 Mar 2017.}

Submit your article to this journal ๘

Џ Article views: 42

View Crossmark data ¿ 


\title{
Effects of composite viscosity and adhesive curing mode on marginal sealing of restorations
}

\author{
Natália Cortez Gutierrez, Graziela Ribeiro Batista, Letícia Carvalho Coutinho \\ Costa Perote, Maria Beatriz Beber Kamozaki, Maria Amélia Máximo de Araújo and \\ Carlos Rocha Gomes Torres
}

Department of Restorative Dentistry, Institute of Science and Technology, São Paulo State University -UNESP, São José dos Campos, Brazil

\begin{abstract}
Objectives: Evaluate the influence of composite viscosity, adhesive systems curing mode and artificial aging on marginal sealing of composite resin restorations. Methods: 240 cavities were prepared in bovine incisors. Teeth were divided in two groups: GR - GrandioSO (Voco), conventional viscosity and GF - Grandioso Heavy Flow (Voco), low viscosity. Each group was divided into 6 subgroups: FM - Futura Bond M (Voco), FDCL and FDCC - Futura Bond DC (Voco), light and chemical cured, CS - Clearfil $S^{3}$ Bond (Kuraray), CDCL and CDCC - Cleafil DC (Kuraray), light and chemical cured. Half of all specimens were subjected to mechanical (300.000) and thermal cycling (1.000). Marginal gap was measured in an optical microscope. For microleakage, specimens were stained in 50\% ammoniacal silver nitrate. Results: For marginal gap mean $(\mu \mathrm{m})$, significant differences were shown for all factors $(p=0.000)$. Results for resin were GR: 28.1 and GF: 40.6; for adhesive CDCC: 28.67, CDCL: 32.25, CS: 34.12, FDCL: 36.10, FM: 36.50 and FDCC: 38.46; and for artificial aging WITHOUT: 29.05 and WITH: 39.65. For microleakage mean ( $\mathrm{mm})$, there were also differences for all factors $(p=0.000)$. Results for resin were $\mathrm{GR}: 2.68$ and GF: 3.46; for adhesive FM: 2.85, CDCC: 3.00, FDCL: 3.08, CDCL: 3.15, CS: 3.16 and FDCC: 3.19 ; and for artificial aging WITHOUT: 2.66 and WITH: 3.48. Conclusion: Composite with conventional viscosity resulted in narrower marginal gaps and less microleakage. CDCC showed less marginal gap formation. The presence of thermo-mechanical cycling increased the values of gap and microleakage.
\end{abstract}

\section{ARTICLE HISTORY}

Received 2 August 2016

Revised 22 February 2017

Accepted 24 February 2017

\section{KEYWORDS}

Microleakage; self-etch adhesive; resin-based composites; marginal gap; thermo-mechanical cycling

\section{Introduction}

Composite resin restorations are increasingly requested by patients, both anterior and posterior teeth, mainly because this material is pleasant aesthetically. Composites have been widely studied and improved substantially since its invention, particularly with regard to color matching, polishing and wear resistance [1]. 
Despite all development, composites remain a technique-sensitive material especially due to the number of steps [1]. Shrinkage and stress resulting from the polymerization are two technical features that need to be further controlled, primarily because such factors are directly related to clinical manifestations such as failures in marginal integrity [2].

The filler content presented in a resin matrix is a factor that can influence these features of composites. Higher viscosity and filler content led to less polymerization shrinkage of composite when compared to the 'high flow or fluids', which typically have lower filler contents [3]. Thus, the incorporation of more filler particles in a resin matrix appeared to be a solution to the reduction of polymerization shrinkage, and also provide an increased hardness, resistance, decreased wear and increased viscosity [4]. On the other hand, those higher viscosity composites are capable of producing higher shrinkage stress because of their greater rigidity, and also have low flow and adaptation to cavity walls when compared to flowable resins $[3,4]$.

In general, the filler content of flowable resins varies around $60 \%$ by weight and $45 \%$ by volume, and viscosity increases significantly when increasing the amount of filler particles [5]. Through the chemical treatment of nano-sized particles surface, this isolated nanoparticles when embedded in a resin matrix, do not behave like a solid but as a liquid, making it possible to produce composite with low viscosity that has high filler content, about $80 \%$ by weight and $70 \%$ by volume. It can be expected that these composites that associate high filler content with low viscosity, could unite the quality of a smaller shrinkage, maintaining a good adaptation and reducing tensions in order to maintain the marginal integrity.

When there is no perfect seal in the restoration margin, marginal gaps are formed [6]. These gaps are considered harmful because they allow the transfer of fluids or materials between the pulpo-dentin organ and the oral environment. This phenomenon is called microleakage [7]. Through this exchange of fluids, there is the possibility of bacterial contamination on the surfaces of cavities which could lead to pulp damage and secondary caries [8].

It is important to remember that not only characteristics of the composite, but also the adhesive characteristics may influence the success of a restoration. Currently, many clinicians prefer to use more simplified adhesive systems, due to its easy way of application [9]. Thus the self-etch adhesives have been widely employed [10].

Although self-etch systems have shown adequate performance in dentin $[11,12]$, several studies have questioned its effectiveness in enamel margins, by its lower etching ability when compared to phosphoric acid [11,13], harming the quality of marginal seal obtained $[14,15]$.

In order to enable its use as a luting agent of indirect restorations and pins, some manufacturers have developed dual-cure self-etching adhesives. Thus, areas that polymerization light is not able to reach resin monomers cure will be totally dependent on the chemical activation system [16-18]. It is important that the hybrid layer is fully cured before the stresses resulting from polymerization shrinkage of composite resin start operating on it, because otherwise this region would only be an area of demineralized collagen surrounded by free monomer. If the chemical system fails, an unsatisfactory sealing can be obtained [18].

Another important technical feature of restorative materials is related to the dimensional changes of the material, which can be caused by polymerization shrinkage of resins and by thermal changes of the oral environment [19]. Masticatory forces and other mechanical 
stresses may aggravate microleakage [19] so it is prudent that in vitro studies use some form of thermal and mechanical stress [20]. So the aim of this study was to evaluate the influence of composite viscosity, adhesive curing mode and thermo-mechanical cycling on marginal sealing of restorations.

\section{Methods}

\section{Specimen's preparation}

240 fresh extracted bovine incisors crowns were used, the enamel of buccal surface was flattened using P 400 grit sandpaper (Fepa-P, Panambra, São Paulo, Brazil), the specimens were embedded in a chemically activated transparent acrylic resin (Jet, Clássico, São Paulo, Brazil) in a cylindrical silicone mold.

A cylindrical cavity of $4 \mathrm{~mm}$ in diameter and $2.5 \mathrm{~mm}$ depth was prepared on the flattened surface of each specimen using a diamond bur (PM85G KG Sorensen, Barueri, Brazil), the margins of the restoration were in enamel and the pulp wall was in dentin.

\section{Experimental group's division}

Specimens were divided into two groups according to the viscosity of the composite resin: GR - GrandioSO (Voco) conventional viscosity and GF - GrandioSO Heavy Flow (Voco) low viscosity, both with high filler content. Each group were divided into six subgroups, according to the adhesive systems: FM - Future Bond M (Voco), FDCL - Futura Bond DC (Voco), light-cured, FDCC - Futura Bond DC (Voco), chemical cured, CS - Clearfil $S^{3}$ Bond (Kuraray), CDCL - Cleafil DC (Kuraray), light-cured and CDCC - Clearfil DC (Kuraray), chemical cured.

Each group was divided into two other subgroups, depending on whether or not they would receive the thermo-mechanical cycling, reaching 24 groups of 10 specimens each. Table 1 shows all materials used.

Table 1. Materials used, manufacturers, components and batch.

\begin{tabular}{|c|c|c|c|}
\hline Material & Manufactures & Components & Batch \\
\hline GrandioSO & $\begin{array}{l}\text { Voco/Cuxhaven/ } \\
\text { Alemanha }\end{array}$ & $\begin{array}{l}\text { Resin Matrix: Bis-GMA, BisEMA, TEGDMA, CQ, Amina, BHT } \\
\text { Inorganic Content: nanoparticles of } \mathrm{SiO}_{2}: 20-40 \mathrm{~nm} \text {; glass- } \\
\text { ceramic: } 1 \mu \mathrm{m} \\
\text { Filler content: } 89 \% \text { by weight and } 73 \% \text { by vol }\end{array}$ & 1029391 \\
\hline $\begin{array}{l}\text { GrandioSO Heavy } \\
\text { Flow }\end{array}$ & $\begin{array}{l}\text { Voco/Cuxhaven/ } \\
\text { Alemanha }\end{array}$ & $\begin{array}{l}\text { Resin Matrix: Bis-GMA, BisEMA, TEGDMA, HEDMA, CQ, } \\
\text { Amina, BHT } \\
\text { Inorganic Content: nanoparticles of } \mathrm{SiO}_{2}: 20-40 \mathrm{~nm} \text {; } \\
\text { glass-ceramic: } 1 \mu \mathrm{m} \\
\text { Filler content: } 83 \% \text { by weight and } 68 \% \text { by vol }\end{array}$ & 1123233 \\
\hline Futurabond M & $\begin{array}{l}\text { Voco/Cuxhaven/ } \\
\text { Alemanha }\end{array}$ & $\begin{array}{l}\text { UDMA, HEMA, methacroyl phosporic acid ester, canphoro- } \\
\text { quinone, BHT and ethanol }\end{array}$ & 1025303 \\
\hline Futurabond DC & $\begin{array}{l}\text { Voco/Cuxhaven/ } \\
\text { Alemanha }\end{array}$ & $\begin{array}{l}\text { Bis-GMA, HEMA, TMPTMA, methacroyl phosporic acid ester, } \\
\text { canphoroquinone, BHT and ethanol }\end{array}$ & 1030392 \\
\hline Clearfil S B Bond & $\begin{array}{l}\text { Kuraray/Tóquio/ } \\
\text { Japão }\end{array}$ & $\begin{array}{l}\text { Bis-GMA, HEMA, canphoroquinone, MDP, hydrophobic } \\
\text { dimethacrylate, ethyl alcohol, water and colloidal silica }\end{array}$ & 000210 \\
\hline Clearfil DC & $\begin{array}{l}\text { Kuraray/Tóquio/ } \\
\text { Japão }\end{array}$ & $\begin{array}{l}\text { Bis-GMA, HEMA, canphoroquinone, MDP, benzoyl peroxide, } \\
\text { ethanol, water and colloidal silica }\end{array}$ & $\begin{array}{l}\text { Liq. A } 00025 \\
\text { Liq. B } 00018\end{array}$ \\
\hline
\end{tabular}




\section{Restorative procedure}

Adhesive systems were applied according to the manufacturer's instructions for $20 \mathrm{~s}$. For FM, FDCL, CS e CDCL, adhesive was light cured for $10 \mathrm{~s}$. FDCC and CDCC remained over the surface for $3 \mathrm{~min}$ and were not light cured.

After adhesive procedure, composites were applied in an incremental technique and were light cured using Elipar TM Free Light 2 (3 M ESPE, St. Paul, MN, USA) for $20 \mathrm{~s}$, with a power density of $1000 \mathrm{~mW} / \mathrm{cm}^{2}$. Power density was measured every 10 specimens using an LED radiometer.

After 24 h, restorations were then polished with P 1200, 2400 and 4000 grit sandpaper (Extec, Enfield, CT, USA) through 30 s each.

\section{Thermo-mechanical cycling}

Specimens were placed at the thermo-mechanical cycling machine (ER 3700 ERIOS Equipamentos técnicos e Científicos Ltda., São Paulo, Brazil) and received 300.000 mechanical cycles. Simultaneously, 1.000 thermal cycles were performed in baths of distilled water for $30 \mathrm{~s}$ at each temperature $\left(5,37\right.$ and $\left.55^{\circ} \mathrm{C}\right)$ with a range of $10 \mathrm{~s}$ between each bath [21]. The load was applied in the center of restoration's occlusal surface.

\section{Marginal gap evaluation}

The biggest marginal gap width in microns for each restoration was measured in an optical microscope [22] (FM-700, Future- Tech, equilam, Tokyo, Japan), with 100× magnification and using the program HDPS-ARS 900 (Future- Tech, equilam, Tokyo, Japan).

\section{Microleakage evaluation}

Specimens had its surface sealed with nail polish varnish, except for an area of $1 \mathrm{~mm}$ around the restoration margins. Then they were immersed in 50\% ammoniacal silver nitrate solution for $24 \mathrm{~h}$, washed for $20 \mathrm{~min}$ and placed on radiographic developer (Kodak, NY, USA) for $8 \mathrm{~h}$ under fluorescent light $[23,24]$. Specimens were sectioned twice in a hard tissue sectioning machine (Labcut, Extec, Enfield, CT, USA), resulting in 4 segments and 8 interfaces for specimen, all internal interfaces were photographed by a digital camera connected to a stereomicroscope (Stemi 2000-C, ZEISS, Oberkochen, Germany) with 32× magnification. The interface with the deepest microleakage penetration was measured in millimeters by Image Tool 3.0 software.

\section{Analysis of composite properties}

To better characterize the composite resins under study, some properties of the composites were measured. Polymerized specimens of $40 \times 6 \times 2 \mathrm{~mm}$ of each resin were made and the elastic modulus was measured by impulse excitation [25] using the device Sonelastic (ATCP, Sao Carlos, Brazil). After that, the Knoop microhardness was measured through microhardness (FM-700, Future-Tech, Equilam, Tóquio, Japão) calibrated with a load of $50 \mathrm{~g}$ for $15 \mathrm{~s}$ [26]. 
The polymerization shrinkage of a $2 \mathrm{~mm}$ portion of each resin was measured using the video-imaging device AccuVol [27] (Bisco, Illinois, USA) and polymerization stress by universal testing machine (DL-200 MF, Emic, Pinhais, PR, Brazil) as proposed by Boaro et al. [28] For all properties, three measurements were performed and the average value of them was considered.

\section{Statistical analysis}

Data were tested for normality using the Kolmogorov - Smirnov test and showed a normal distribution. Data were then statistically analyzed using three-way analysis of variance (ANOVA), followed by Tukey's test to identify pairwise differences. The correlation coefficient for marginal gap and microleakage was also evaluated.

\section{Results}

\section{Marginal gap}

The results of three-way ANOVA test for marginal gap evaluation showed that all factors evaluated (composite, adhesive and cycling) were significantly different, as well as the interactions between them $(p=0.00)$, with the exception of the interaction between composite and cycling $(p=0.15)$.

The results revealed that in general the conventional viscosity composite had lower mean of marginal gap width in microns when compared to the flowable composite. Clearfil DC showed lowest marginal gap than Futurabond DC. Clearfil $S^{3}$ and Futurabond $M$ were not statistically different.

Specimens that were submitted to thermo-mechanical cycling showed higher values of marginal gap. Figure 1 shows the mean values of marginal gap width for all groups, their standard deviation and pairwise differences.

\section{Microleakage}

The results of three-way ANOVA test for microleakage evaluation showed that all factors evaluated were significantly different, as well as the interactions between them $(p<0.05)$. In general, specimens that were restored with conventional viscosity composite had lower average of microleakage in millimeters than those restored with flowable composite. Futurabond DC and Clearfil DC, were not statistically different. Futurabond M showed less microleakage than Clearfil $S^{3}$. Considering different curing modes for the same adhesive, light or chemical cure had no influence in microleakage results.

In agreement with the results showed on marginal gap evaluation, the presence of thermo-mechanical cycling also resulted in higher values of microleakage. Figure 2 shows the mean values of microleakage for all groups, their standard deviation and pairwise differences.

\section{Correlation}

Moderate positive correlation was found between the variables marginal gap and microleakage, with $r=0.57$. Thus, the larger the measured gaps the higher the microleakage values. Figure 3 shows the correlation. 


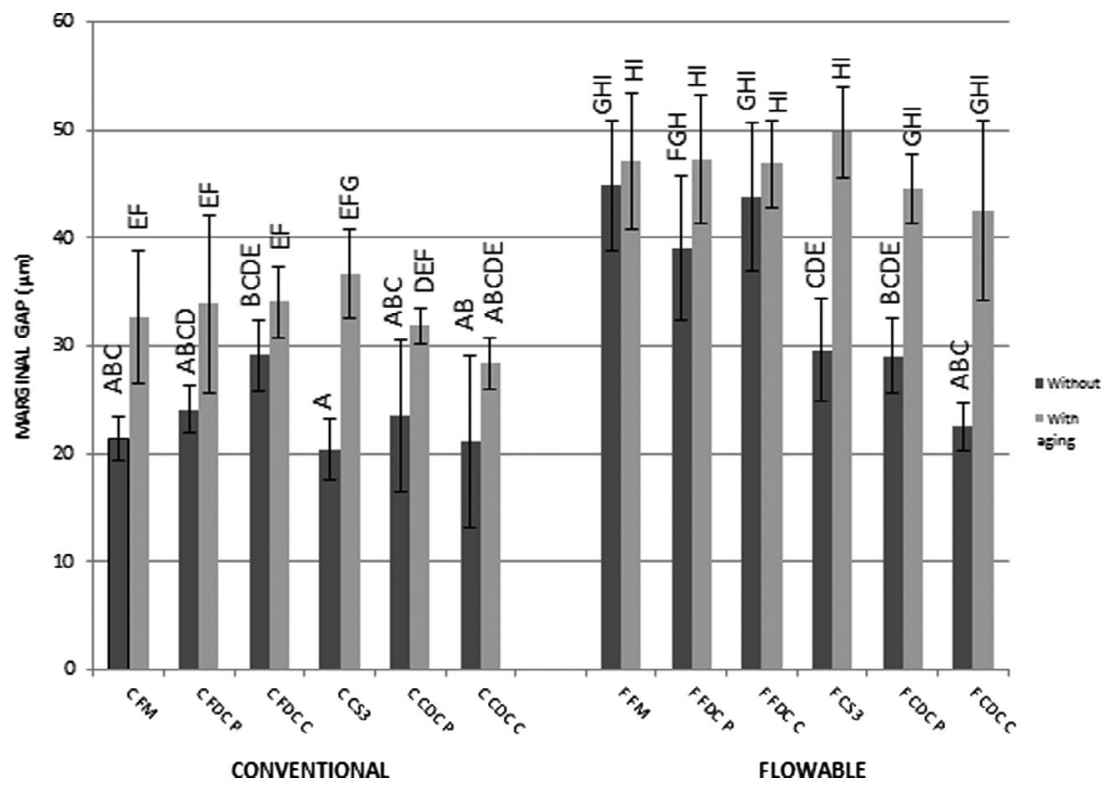

Figure 1. Standard deviation and mean values of marginal gap width for the different groups. Note: * Sets with different letters are statistically different.

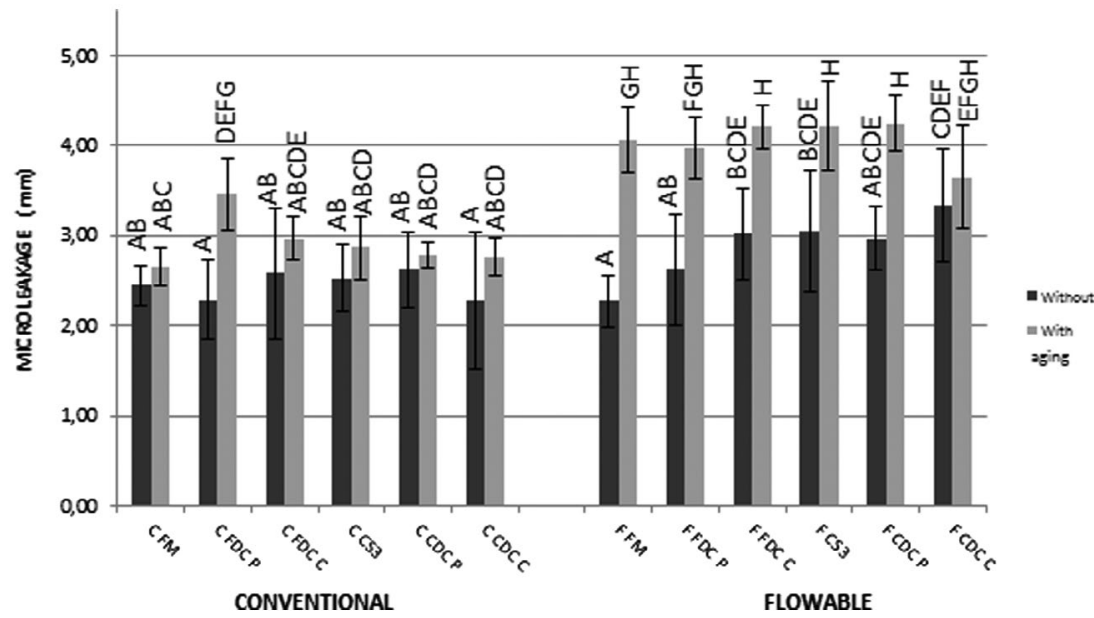

Figure 2. Standard deviation and mean values of microleakage for the different groups. Note: *Sets with different letters are statistically different.

\section{Composite properties}

Even though, the flowable composite presented lower elastic modulus (12.85 GPa flowable $\times 21.62 \mathrm{GPa}$ conventional), still showed higher polymerization shrinkage (3.66\% flowable $\times 2.56 \%$ conventional $)$ and polymerization stress $(6.22 \mathrm{~N}$ flowable $\times 3.51 \mathrm{~N}$ conventional $)$ than conventional. Table 2 shows these results. 


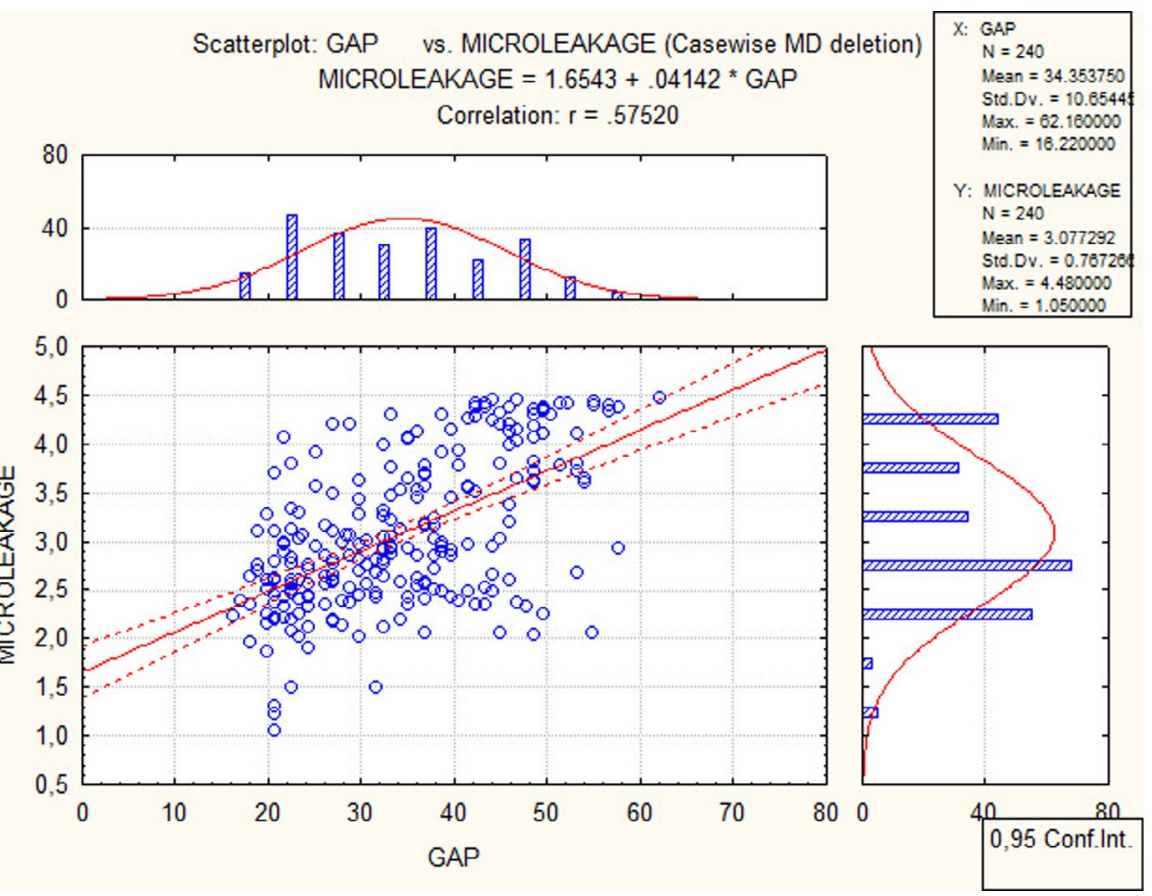

Figure 3. Correlation between gap and microleakage.

Table 2. Composite properties.

\begin{tabular}{lcc}
\hline Properties & Conventional & Flow \\
\hline Elastic Modulus (GPa) & 21.62 & 12.85 \\
Microhardness (HK) & 93.19 & 40.27 \\
Polymerization shrinkage (\%) & 2.56 & 3.66 \\
Polymerization stress (N) & 3.51 & 6.22 \\
\hline
\end{tabular}

\section{Discussion}

GrandioSO Heavy flow had higher means of marginal gap width and microleakage than the conventional viscosity composite. By analyzing some properties of both composites (Table 2), we can observe that the flowable with high filler content still had higher polymerization shrinkage and polymerization stress than conventional, even with lower elastic modulus. According to previous study both composites presented similar bond strength [29].

Showing that lower elastic modulus, which could improve the outcome of the restoration, was not enough to compensate for its large shrinkage, resulting in a greater generation of gaps and microleakage by flowable composite. If the composite showed the same degree of polymerization shrinkage, possibly the resin with higher modulus of elasticity, the conventional, would lead to increased gap formation than the flowable [30]. However, the flowable composite studied showed higher polymerization shrinkage.

After curing, composite begins to transfer stress to the cavity walls. The correlation between polymerization shrinkage and gap formation exists so the greater the contraction 
the greater the gap generated [30]. The relationship between lower elastic modulus and lower shrinkage stress is not really direct and absolute, since the behavior of a composite resin in relation to its shrinkage and its generation of polymerization stress, is material dependent. Thus, the type and amount of monomers and the type, number and size of the filler content are of great influence on those properties [31].

The biggest difference in the composition of the two composites studied relates to diluents monomers. According to Atai et al. total shrinkage strain of the Bis-GMA/TEGDMA mixtures decreases with increasing Bis-GMA percent in the mixture due to its higher molecular weight [32]. GrandioSO Heavy flow has a higher percentage of diluents monomers with low molecular weight, such as TEGDMA and HEDMA, which show high volumetric shrinkage and high contraction stress values, due to increased conversion rate [31]. This can justify flowable composite higher values of gap and microleakage when compared to conventional viscosity.

One possible approach to improve their performance might be to pre-heat these materials, since it has been shown that pre-heating prior to photo activation decreases shrinkage stress formation of resin composites without compromising the degree of conversion [33].

In marginal gap evaluation the adhesive CDCC had lower values compared to all other adhesives used. It also showed less marginal gap that the same adhesive when light cured. The study of Taubock et al., showed that shrinkage stress formation of resin-based materials is much lower when only self-curing takes place, mainly due to differences in the velocity of polymerization between activation modes. Since chemical cure extends the pre-gel phase and consequently the time available for viscous flow to relieve shrinkage stresses [34].

Griffiths et al. showed that the use of an experimental primer that was not light cured led to less microleakage than the experimental primer with photoinitiators that was light cured [35].

For Futurabond DC, the curing mode did not generate significant differences. Both, dual and chemical, cure of adhesives are capable of producing similar bond strength to light polymerization. But for this, is vital to have a complete polymerization and action of the chemical activators components, since an incomplete polymerization may be able to allow the diffusion of water, which will further impair the polymerization reaction, as consequently affect the mechanical properties, bond strength and compromise the longevity of the restoration [18].

Regarding microleakage, the curing mode of adhesives did not result in significant differences and FM presented the best results and had significant difference when compared to the also 7th generation, CS (Figure 2).

Self-etch adhesives can be classified according to their aggressiveness, which is related to its $\mathrm{pH}$. Are considered to be aggressive or strong those with $\mathrm{pH}<1$, moderate or intermediate between 1 and 2 , and mild those with $\mathrm{pH}>2$. The self-etching adhesives with lower $\mathrm{pH}$ values are more acidic and therefore are capable of producing a more pronounced pattern of enamel conditioning [36,37]. This could explain the better results of FM than CS, because its acid primer is moderate with $\mathrm{pH}=2$ and $\mathrm{CS}$ is mild with $\mathrm{pH}=2.7$.

In regard of thermo-mechanical cycling factor, analyzing Figures 1 and 2, we note that for all groups where the cycling was performed, higher marginal gaps and microleakage were found when compared to their corresponding non cycling groups.

The temperature variation associated with different coefficients of linear thermal expansion of the tooth and restorative materials, would lead to different behaviors and rates of 
expansion and shrinkage. The mechanical cycling, submit the restoration to stresses and load, which could lead to deformations and increase the space between tooth and restoration $[19,38]$.

The linear coefficient of thermal expansion (LCTE) of dentin is 8.3 and enamel is 11.4. Until today, none composite material has achieved the same LCTE as tooth. LCTE of GR resin is 27.3 and GF is 38.6, this could explain why in general, the groups treated with flowable composite suffered major negative influence of cycling than the groups treated with the conventional resin [4]. In addition, this composite presents higher values of shrinkage and polymerization stress than the conventional.

However, it is important to notice that even the groups that were not submitted to cycling also showed the presence of gap and microleakage. This was also observed in the study of Eakle in 1986, the author suggested that this may prove that composite shrinkage only is capable of producing gaps [39].

Despite their limitations, in vitro studies are still primordial and considered a crucial preclinical research approach with which to investigate the numerous restorative configurations that cannot be efficiently and rapidly tested in vivo [40].

\section{Conclusion}

Although promising and providing improvements in physical properties, the flowable composite with high filler content still present lower results than those of conventional viscosity resins, in respect to the marginal adaptation and microleakage. It was also observed that differences in adhesive curing mode had little influence on the evaluated parameters and that the presence of thermo-mechanical cycling lead to worst adaptation and sealing ability. Moderate positive correlation was found between gap and microleakage.

\section{Clinical relevance}

Viscosity of high filler content composites influenced restoration sealing, with worse results to flowable ones.

\section{Disclosure statement}

No potential conflict of interest was reported by the authors.

\section{References}

[1] Leinfelder KF. Posterior composite resins: the materials and their clinical performance. J Am Dent Assoc. 1995;126(5):663-676.

[2] Weinmann W, Thalacker C, Guggenberger R. Siloranes in dental composites. Dent Mater. 2005;21(1):68-74.

[3] Moreira da Silva E, dos Santos GO, Guimarães JG, et al. The influence of C-factor, flexural modulus and viscous flow on gap formation in resin composite restorations. Oper Dent. 2007;32(4):356-362.

[4] Rawls H, Esquivel-Upshaw J. Resinas Restauradoras. In Anusavice K, editor. Phillips Materiais Dentários. Rio de Janeiro: Elsevier; 2005. p. 375-417.

[5] Tauböck TT, Zehnder M, Schweizer T, et al. Functionalizing a dentin bonding resin to become bioactive. Dent Mater. 2014;30(8):868-875. 
[6] Youngson CC, Grey NJ, Jones JG. In vitro marginal microleakage: examination of measurements used in assessment. J Dent. 1990;18(3):142-146.

[7] Ciucchi B, Bouillaguet S, Delaloye M, et al. Volume of the internal gap formed under composite restorations in vitro. J Dent. 1997;25(3-4):305-312.

[8] Brannstrom M, Nordenvall kJ. Bacterial penetration, pulpal reaction and the inner surface of concise enamel bond. Composite fillings in etched and unetched cavities. J Dent Res. 1978;57(1):3-10.

[9] Duarte S, Perdigão J, Lopes MM. Effect of dentin conditioning time on nanoleakage. Oper Dent. 2006;31(4):500-511.

[10] Pashley DH, Tay FR. Aggressiveness of contemporary self-etching adhesives. Part II: etching effects on unground enamel. Dent Mater. 2001;17(5):430-444.

[11] Frankenberger R, Tay FR. Self-etch vs etch-and-rinse adhesives: effect of thermo-mechanical fatigue loading on marginal quality of bonded resin composite restorations. Dent Mater. 2005;21(5):397-412.

[12] van Dijken JW, Pallesen U. Four-year clinical evaluation of Class II nano-hybrid resin composite restorations bonded with a one-step self-etch and a two-step etch-and-rinse adhesive. J Dent. 2011;39(1):16-25.

[13] Van Meerbeek B, De Munck J, Yoshida Y, et al. Buonocore memorial lecture. Adhesion to enamel and dentin: current status and future challenges. Oper Dent. 2003;28(3):215-235.

[14] Hamouda IM, Samra NR, Badawi MF. Microtensile bond strength of etch and rinse versus self-etch adhesive systems. J Mech Behav Biomed Mater. 2011;4(3):461-466.

[15] Loguercio AD, Reis A, Bortoli G, et al. Influence of adhesive systems on interfacial dentin gap formation in vitro. Oper Dent. 2006;31(4):431-441.

[16] Oooka S, Miyazaki M, Takamizawa T, et al. Influence of adhesive polymerization mode on dentin bond strength of direct core foundation systems. J Oral Sci. 2004;46(3):185-189.

[17] O'Keefe KL, Powers JM. Adhesion of resin composite core materials to dentin. Int J Prosthodont. 2001;14(5):451-456.

[18] de Menezes MJ, Arrais CA, Giannini M. Influence of light-activated and auto- and dualpolymerizing adhesive systems on bond strength of indirect composite resin to dentin. J Prosthet Dent. 2006;96(2):115-121.

[19] Trowbridge HO. Model systems for determining biologic effects of microleakage. Oper Dent. 1987;12(4):164-172.

[20] Kidd EA. Microleakage: a review. J Dent. 1976;4(5):199-206.

[21] Vinay S, Shivanna V. Comparative evaluation of microleakage of fifth, sixth, and seventh generation dentin bonding agents: an in vitro study. J Conserv Dent. 2010;13(3):136-140.

[22] Francisconi LF, Graeff MS, Martins LM, et al. The effects of occlusal loading on the margins of cervical restorations. J Am Dent Assoc. 2009;140(10):1275-1282.

[23] Tay FR, Pashley DH, Yoshiyama M. Two modes of nanoleakage expression in single-step adhesives. J Dent Res. 2002;81(7):472-476.

[24] Perdigao J, Monteiro P, Gomes G. In vitro enamel sealing of self-etch adhesives. Quintessence Int. 2009;40(3):225-233.

[25] Radovic M, Lara-Curzio E, Riester L. Comparison of different experimental techniques for determination of elastic properties of solids. Mater Sci Eng A. 2004;368:56-70.

[26] Obici AC, Sinhoreti MAC, Sobrinho LC, et al. Evaluation of depth of cure and Knoop hardness in a dental composite photo-activated using different methods. Braz Dent J. 2004;15(3):199-203.

[27] Fu J, Liu Wenjia, Hao Zhichao, et al. Characterization of a low shrinkage dental composite containing bismethylene spiroorthocarbonate expanding monomer. Int $\mathrm{J} \mathrm{Mol}$ Sci. 2014;15(2):2400-2412.

[28] Boaro LC, Gonçalves F, Guimarães TC, et al. Polymerization stress, shrinkage and elastic modulus of current low-shrinkage restorative composites. Dent Mater. 2010;26(12):1144-1150.

[29] Batista GR, Barcellos DC, Torres CRG. Effect of adhesive type and composite viscosity on the dentin bond strength. J Adhes Sci Technol. 2016;30(8):842-850.

[30] Peutzfeldt A, Asmussen E. Determinants of in vitro gap formation of resin composites. J Dent. 2004;32(2):109-115. 
[31] Cadenaro M, Marchesi G, Antoniolli F, et al. Flowability of composites is no guarantee for contraction stress reduction. Dent Mater. 2009;25(5):649-654.

[32] Atai M, Watts DC, Atai Z. Shrinkage strain-rates of dental resin-monomer and composite systems. Biomaterials. 2005;26(24):5015-5020.

[33] Tauböck TT, Tarle Z, Marovic D, et al. Pre-heating of high-viscosity bulk-fill resin composites: effects on shrinkage force and monomer conversion. J Dent. 2015;43:1358-1364.

[34] Tauböck TT, Bortolotto T, Buchalla W, et al. Influence of light-curing protocols on polymerization shrinkage and shrinkage force of a dual-cured core build-up resin composite. Eur J Oral Sci. 2010;118(4):423-429.

[35] Griffiths BM, Watson TF, Sherriff M. The influence of dentine bonding systems and their handling characteristics on the morphology and micropermeability of the dentine adhesive interface. J Dent. 1999;27(1):63-71.

[36] Tay FR, Pashley DH. Aggressiveness of contemporary self-etching systems. I: depth of penetration beyond dentin smear layers. Dent Mater. 2001;17(4):296-308.

[37] Salz U, Mücke A, Zimmermann J, et al. pKa value and buffering capacity of acidic monomers commonly used in self-etching primers. J Adhes Dent. 2006;8(3):143-150.

[38] Momoi Y, Iwase H, Nakano Y, et al. Gradual increases in marginal leakage of resin composite restorations with thermal stress. J Dent Res. 1990;69(10):1659-1663.

[39] Eakle WS. Effect of thermal cycling on fracture strength and microleakage in teeth restored with a bonded composite resin. Dent Mater. 1986;2(3):114-117.

[40] Dietschi D, Argente A, Krejci I, et al. In vitro performance of class I and II composite restorations: a literature review on nondestructive laboratory trials - Part II. Oper Dent. 2013;38(5):E182E200. 